10

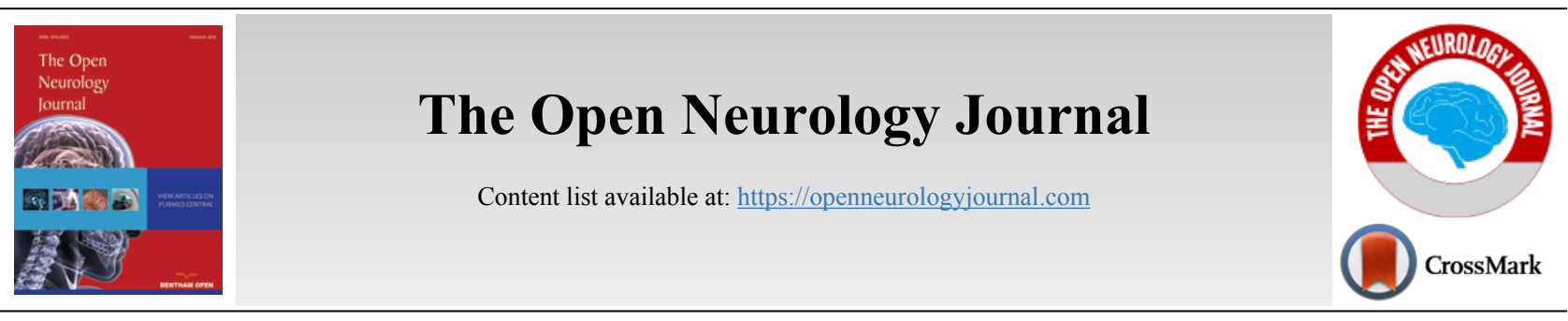

RESEARCH ARTICLE

\title{
Long Term Compliance for MS Patients in Treatment with Disease Modifying Drugs (DMDs)
}

\section{Lara Gitto*}

CEIS Economic Evaluation \& HTA, University of Rome “Tor Vergata”, Via Columbia, 2 - 00133 Roma, Italy

\begin{abstract}
:
Background:

Multiple Sclerosis (MS) is one of the most common causes of neurological disability in young and middle-aged adults. Patients with MS face many challenges, both physical and emotional, and see an overall reduction in their autonomy. There is no definitive treatment for MS, though Disease Modifying Drugs (DMDs) have proved effective in reducing the frequency and severity of relapses. Unfortunately, long-term adherence to these therapies is a significant challenge due to practical difficulties as well as a general distrust towards the drugs .

\section{Objective:}

This study follows an original research carried out in 2008. In the first study, patients answered questions on their clinical history and expressed their judgment on the pharmacological treatment, their perceived effectiveness and factors that may undermine compliance. They have been recalled after two years to verify if the reported symptoms have changed and to assess how their knowledge of the disease and "acceptance" of the treatment have been modified.

Methods:

In spite of the relatively high number of patients participating in the first study (141 patients followed at a single neurological centre), only 16 patients have completed the questionnaire for the long-term survey. A detailed descriptive analysis has been carried out, as well as a pairwise correlation analysis.

\section{Results and Conclusions:}

The interviews carried out gave an insight into how patients' behavior may have changed over time. Compliance rate is different in newlydiagnosed patients and long-term patients; the latter are more likely to be compliant, given their personal experience with the disease. Communications with neurologists and health personnel should aim at forming therapeutic alliances with patients and detecting their preferences for a qualitatively adequate assistance throughout their illness.
\end{abstract}

Keywords: Multiple sclerosis, Long-term compliance, Disease modifying drugs, Injectable treatments, Interferon- $\beta$, Glatiramer acetate, Pairwise correlations.

Article History $\quad$ Received: October 11, 2018

Revised: November 14, 2018

Accepted: December 18, 2018

\section{INTRODUCTION}

\subsection{Treatments for MS. Adherence, Persistence and Compliance}

MS is one of the most common causes of neurological disability in young and middle-aged adults [1]. MS is highly unpredictable: rarely are any two patients alike in the presentation, duration and progression of symptoms [2]. Its various

* Address correspondence to this author at the CEIS Economic Evaluation \& HTA, University of Rome "Tor Vergata”, Via Columbia, 200133 Roma, Italy; Tel: +39 339 8958858; E-mail: Gitto@CEIS.uniroma2.it symptoms can be associated with motor deficits (fatigue, paralysis, coordination disturbances), sensory problems, speech and vision (blurred or double vision) impairments, and sphincter and bladder malfunctions [3].

Patients with MS face many challenges, both physical and emotional $[4,5]$, and see an overall reduction in their autonomy.

There is no definitive treatment for MS. However, in the past two decades, Disease Modifying Drugs (DMDs) have proved effective in reducing the frequency and severity of relapses, the progression of disability and the appearance of 
new central nervous system lesions. [6 - 9].

The most common and well known drugs are interferon beta $1 \alpha$ (IFN- $\beta 1 \alpha$ ), interferon beta $1 \beta$ (IFN- $\beta$ ) and glatiramer acetate (GA). These are injectable medications and they are "first line" treatments for $\mathrm{MS}^{1}$.

In the past years, other pharmacological treatments such as fingolimod or the monoclonal antibody natalizumab have been made available as "second line" treatments for MS. They are recommended for patients with highly active MS who show an inadequate response to first line therapies $[10,11]$.

Although new drugs are being increasingly prescribed, both as first and second line Disease Modifying Therapies (DMTs), IFN- $\beta$ and GA are still among the most frequently employed drugs due to their established safety profile.

According to the OsMed National Report [12], when the interviews for this study were carried out in 2010, expenditure and consumption of DMTs such as IFN- $\beta$ and GA in Italy were the following: IFN- $\beta$ gross per capita expenditure $3,81 €(\%=$ $8,2)$, Defined Daily Dose $/ 1000$ 0,6 ( $\%=8,2)$; GA gross per capita expenditure $0,84 €(\%=1,8)$, Defined Daily Dose $/ 1000$ $0,1(\%=1,2)$. Therefore, DMDs were the most prescribed drugs in 2010 .

Nowadays, the picture has changed: IFN- $\beta$ and GA account respectively for $25.1 \%$ and $10 \%$ of the market for drugs for MS, while the remaining $65 \%$ is shared between first and second line therapies, including oral drugs (such as Fingolimod) and infusive drugs (Natalizumab) [13].

An early diagnosis allows patients to begin a therapy with a pharmacological treatment within a short time after onset and thus delay the degenerative progression of MS [14]. The choices regarding the most suitable pharmacological treatment and its timing may rely on the patient's and physician's joint decision $[15,16]$.

There are some advantages in beginning a pharmacological treatment early. It has been shown that patients who start treatment at a later stage have a greater risk of reaching Expanded Disability Status Scale (EDSS) 4. Although this disability score is still moderate (compared to EDSS scores higher than 4.5 , which are regarded as more severe and impairing individuals' daily activities), according to clinical evidence, this may increase by $7.4 \%$ for every year of delay in treatment start after MS onset [17].

In spite of a high initial compliance, long-term adherence to DMTs is a significant challenge, due to practical difficulties in their administration, often coupled with a general distrust towards these drugs. In many cases, patients with MS do not experience another relapse or significant signs or symptoms for months or years following diagnosis, which may make it difficult for them to accept that they need to routinely selfinject [18].

Once they have accepted the need for the treatment, patients must then persist with the therapy.

Compliance as a human attitude has been studied in the literature: it conforms to basic facts of human character (propensity to misperceive risk, biological roots of instrumental conditioning) [19].

A study from 2005 [20] was aimed at ascertaining whether the frequency and timing of IFN- $\beta$ discontinuation in a cohort of MS patients, as well as the disease type (relapsing-remitting or progressive), were reasons for discontinuation and influenced the stopping rates. It was found that patients stopped due to side effects after a median of 13 months and due to a failure of therapy after a median of 35 months.

While compliance involves following the instructions on the prescription (i.e., taking the medication at the right time, at the right dose, on the right day), persistence is more difficult to observe among MS patients after the first 6 months of therapy. It has been observed how discontinuation rates during the first 6 months of treatment ranges from $9 \%$ to $20 \%$, although abandonment of a MS treatment regimen can happen at any time [21].

Adherence to DMTs in the long term, i.e. persistence, is a key factor to their success, whereas a lack of adherence can lead to treatment failure, increased hospitalizations and relapse rates, as well as resulting in higher costs for the health system $[22,23]$.

Current evidence suggests that improved treatment adherence may be one of the best strategies for managing MS and, in this perspective, several studies have analyzed what makes patients persistent to DMTs [24 - 26].

Some of the barriers to treatment adherence among MS patients include perceived efficacy concerns, adverse events, inconvenience and needle phobia (associated with injectable DMTs). IFN- $\beta 1 \alpha$, IFN- $\beta 1 \beta$ and GA require a schedule of either subcutaneous or intramuscular injections, ranging in frequency from daily to weekly. Multiple factors can contribute to the inability to self-inject: many patients are misinformed about the risks of self-injection and believe it to be unsafe or even potentially life-threatening; others are not aware about how best to manage injection pain and side effects [27]. To overcome this problem, patients with injection phobia often select a family member/friend/other to conduct the injection a factor strongly linked to poor long-term adherence [28, 29].

According to some contributions in the literature, the rate of discontinuation has been found to be significantly higher among patients taking an injectable DMT, compared to patients receiving an infusion or oral DMT [30].

Moreover, after starting the treatment, patients may perceive only its negative aspects: those who have had a benign course of the disease may question the usefulness of undergoing a pharmacological treatment involving fairly heavy administration and side effects (such as flu-like symptoms for IFN- $\beta$ ).

A poor compliance can have relevant economic consequences: a remarkable level of expenditure is associated with MS, both for patients undergoing the treatment (cost of drugs and productivity losses due to side effects after DMDs administration, etc.) and for those who do not take the drug or take it discontinuously (higher probability of relapses) [31, 32].

\footnotetext{
${ }^{1}$ These treatments are described in detail in the Appendix.
} 
Therefore, a higher compliance saves resources by avoiding the effects of managing the relapse [33]; there is also greater collaboration by the patient in terms of coping, since he/she wishes to collaborate with the doctor to identify the best therapeutic path $[34,35]$.

Overall, patients who comply with the prescribed therapeutic program will have better outcomes than patients who do not comply. This conclusion is true for both short-term and long-term compliance: a number of variables related to the likelihood that an individual will comply, even in the long term, has been studied. In a research focusing on long-term compliance for cardiac patients, the effort required for patients to change their lifestyles was also analyzed [36].

Long-term compliance may depend on whether patients recognize that the therapy has had a positive effect: in this case, they could be strengthened in their beliefs in the effectiveness of the treatment and consider the side effects negligible when compared to a greater stability of their clinical conditions [37, 38].

This study follows an original research carried out in 2008 [16] and it is aimed at analyzing long term compliance for a cohort of MS patients in treatment with DMDs at a neurological centre in Southern Italy. The patients enrolled in the first study reported their clinical history and expressed their judgments on the pharmacological treatment, the perceived effectiveness and the factors that may undermine compliance to the medical treatment. The same patients have been recalled after two years and asked to assess the extent to which their knowledge of the disease has been modified and their degree of "acceptance" of the medical treatment.

The objective is to verify which factors are determinant in a compliant behavior. This could help physicians (neurologists) identify the right approach to follow by suggesting strategies that strengthen the therapeutic alliance between patients and physicians [34, 35].

Unfortunately, in spite of the high number of patients participating in the first study $(n=141)$, only 16 patients have completed the interviews for this second survey: this evidence could in itself signify patients' loss of interests in describing their health status and expectations a second time.

The next section describes the questionnaire developed and the data collected in details. A descriptive analysis has been carried out, looking for the pairwise correlation among the variables likely to determine compliance in the long term; the evidence that could be obtained is reported in section 3 . The discussion related to considerations that may be raised and future lines of research is presented in section 4 and concludes the paper.

\section{DATA AND METHODS}

In the present case study, patients treated with DMDs (IFN- $\beta$ and GA) who had already participated in a first compliance survey [16], carried out at the Centro Studi Neurolesi "Bonino Pulejo" in Messina, Southern Italy, were considered.

Most of the questions asked in the previous survey to assess compliance were re-proposed; in addition, patients were asked to evaluate their health conditions over the past two years.

The anonymity of the questionnaire was guaranteed to patients. When they participated in the first survey, they were given an identification code. Patients re-called for this second survey were asked to communicate this identification code in order to match the two questionnaires. This could potentially explain the low number of responses: patients might have failed to remember the identification code and therefore chose not to submit the survey.

The questionnaire was divided into five sections.

The first section was about collecting general information (age, gender, marital status, education, income level).

Questions in the second section focused on the treatment followed and the place of residence. This allowed to evaluate the distance that the patient had to travel to go to the neurological center and collect the drug.

In the third section of the questionnaire, patients were asked to describe their clinical history again (how many years living with MS, health status before scale diagnosis on a range from 1 to 10, co-morbidities, number of relapses, time since the last relapse and evaluation on its severity).

Patients were specifically asked if they believed their health status had improved, worsened or remained unchanged over the past two years.

Another section of the questionnaire asked specific questions on DMDs therapy, such as the length of the treatment, whether the therapy was believed to present disadvantages and what these disadvantages were (unlike other questions, this question is open-ended, so as to allow patients to freely express their opinions). It also asked patients to indicate which side effects were being experienced, especially after having administered the pharmacological treatment, and whether it was necessary to take other drugs to counter them.

In the questionnaire, patients were asked once more to assess the level of discomfort related to the administration of the therapy $(1=$ minimum discomfort, $5=$ maximum discomfort) and list the most common side effects.

The questionnaire then asked if the patient had been compliant towards the treatment. If the patient had interrupted the pharmacological treatment in the last two years, he/she was asked to state approximately how many times this had happened and why. Several motivations were proposed: relapses occurred despite therapy; the patient feeling in perfect health and the therapy seeming superfluous; the side effects being a nuisance; other patients having been seen suffering severe health consequences in spite of the treatment; the administration of the drugs being difficult.

In light of the current level of health, patients were asked to formulate a judgment on the effectiveness of the therapy. In particular, the patient had to rate from 1 to $5(1=$ minimally effective, $5=$ maximally effective) how much he/she thought that the DMDs therapy had been effective in the past 2 years.

The questionnaire also asked whether the symptoms of the disease after having started the therapy had remained un- 
changed (a circumstance that corresponds to a stability of the clinical picture, hence a high effectiveness of the treatment) and if not which symptoms no longer manifested and which either reduced or increased in intensity.

The last section of the questionnaire concerned the patient's awareness level: from the time of diagnosis to the time of the interview, had the patients ever considered if their knowledge of the disease and the information they had had remained the same, was augmented, or if they felt they knew less than before? If the patients had reported increased information and knowledge, had their convictions about the evolution of the disease changed due to additional information, both positive or negative, they might have received? On the other hand, was the information they already had sufficient for managing the disease?

The last and most complex question concerned the risk of worsening of the disease, both minimum and maximum, to be expressed within a range, from 0 to 100 .

At the time of the interview, the patients were all taken care of at the same neurological centre; they were interviewed, and/or asked to fill the questionnaire forms, while they waited for a medical consultation or to collect a drug.

In the majority of cases, the questionnaire was completed independently by the patients; the psychologists of the center, who had already assisted the patients in completing the previous questionnaire, were available for any clarifications.

\section{RESULTS}

Out of the more than 140 patients contacted for the present survey, only 16 patients returned the completed questionnaires.

The reluctant behavior observed in completing the survey might indicate patients' loss of interest in reporting their clinical situations; patients who had already replied to the questionnaire employed for the first study may have thought this was a mere replica of the previous one and not a comparison across very different stages of the treatment. They could also have read the items and decided not to submit the questionnaire given that their condition and expectations had remained unchanged.

In any case this behavior is evidence of the kind of information that can be obtained by patients: they can be extremely precise in describing their health status and in stating their preferences concerning the treatment to follow, but they expect not to be interviewed again to confirm what they perceive as "obvious".

Not all the variables in the study present continuous values. Some variables have only two categories and are, therefore, dichotomous (such as gender; level of education primary school, high school, graduate education; married status; type of drug administered, etc.). For example, the subject can reply to the question about whether they are married with either "Yes" or "No".

Ordinal variables, on the other hand, have two or more categories that can be ordered or ranked (such as the judgment about how beneficial is the pharmacological treatment, ranked from 1 to 5 , or how difficult is the administration of the drugs, also ranked from 1 to 5 ).

Tables 1-4 shows the answers to the various items in the questionnaire, given by the 16 patients who replied to the survey.

Tables 1a and 1b present general information, distinguishing between parametric (such as patients' age, years living with the disease) and non parametric variables (gender, education, income, marital status).

On average, the patients who replied to the second wave of the survey were 41 years old (minimum age $=30$, maximum ages $=55$ years old); about two third were women. The age range of the patients when they were diagnosed was 20-40 years the time of life when one is more productive, both at work and at school.

Seven patients completed high school, whereas 4 patients had completed graduate or post graduate education. Ten people were married. The level of income was lower than $30,000 €$ for all the respondents.

The average distance between patient's residence and the neurological centre was almost $54 \mathrm{~km}$, although one patient lived in a town at $219 \mathrm{~km}$ from the centre.

Table 2 reports information about symptoms experienced and pharmacological treatment followed.

IFN- $\beta 1 \alpha$ (Rebif $^{\circ} 22$ or 44$)$ was the type of drug more frequently used. GA was the least used in the sample (only 2 patients).

The patients experienced many varied symptoms. In the table, the symptoms have been grouped based on the classification given by patients and according to functional systems interested by the disease: pyramidal, sensory, cerebellar, brainstem, visual, sphincter, other.

Patients had followed a pharmacological treatment for 8 years on average (time interval going from 3 to 15 years) and the majority $(62.5 \%)$ reported disadvantages and side effects (93.7\%). Fifty-six per cent of patients stated they need to take other drugs to contrast side effects due to the treatment. Table $\mathbf{3}$ reports the patients' experiences related to relapse.

Patients were asked to rate their level of health before the disease onset on a scale from 1 to 10 . They said their health condition could be judged with a score from 7 to 10 (average value of 9.250).

However, since the disease onset, they experienced various relapses. One patient said the relapses occurred almost every month, reaching the number of approximately 140 in 7 years of disease. For the $43.7 \%$ of patients, the severity of relapses was approximately the same and relapses had occurred recently (only for the $25 \%$ of patients, the last relapse occurred more than 5 years ago). Relapses were treated pharmacologically and in some case with a short hospitalization. Of course, the way relapses are experienced is extremely varied and reflects the different strategies of coping implemented by patients as well as their different perceptions.

Table 4 presents the crucial information for the present study: how symptoms have evolved with time (whether they 
have not appeared since the first attack, have improved, have remained the same or have worsened), how the awareness and the knowledge about the disease have evolved, and a judgment about the benefits obtained through the pharmacological treatment.

Table 1a. General information (for parametric variables - normal distribution, Gaussian distribution).

\begin{tabular}{|c|c|c|c|c|}
\hline Variable & Mean & Stand. Deviation & Min & Max \\
\hline Age & 41.125 & 6.682 & 30 & 55 \\
\hline Distance (km) & 53.819 & 53.489 & 7.8 & 219 \\
\hline Age at diagnosis & 31.687 & 6.610 & 21 & 46 \\
\hline Years of disease & 9.187 & 3.885 & 3 & 16 \\
\hline
\end{tabular}

Table 1b. General information (for non-parametric variables, non-Gaussian distribution).

\begin{tabular}{|c|c|c|}
\hline Variable & Absolute Value (n) & Relative Value \\
\hline $\begin{array}{c}\text { Gender } \\
\text { males } \\
\text { females }\end{array}$ & $\begin{array}{c}6 \\
10\end{array}$ & $\begin{array}{l}0.5[50 \%\} \\
0.5[50 \%]\end{array}$ \\
\hline $\begin{array}{c}\text { Education } \\
\text { Compulsory education } \\
\text { High school } \\
\text { Graduate }\end{array}$ & $\begin{array}{l}5 \\
7 \\
4\end{array}$ & $\begin{array}{l}0.3[30 \%] \\
0.4[40 \%] \\
0.3[30 \%]\end{array}$ \\
\hline $\begin{array}{c}\text { Income } \\
<5000 € \\
5001-15.000 € \\
15.001-30.000 € \\
>30.000 €\end{array}$ & $\begin{array}{l}3 \\
6 \\
6 \\
1\end{array}$ & $\begin{array}{l}0.2[20 \%] \\
0.4[40 \%] \\
0.3[30 \%] \\
0.1[10 \%]\end{array}$ \\
\hline $\begin{array}{c}\text { Marital status } \\
\text { Married } \\
\text { Single } \\
\text { Widowed }\end{array}$ & $\begin{array}{c}10 \\
5 \\
1\end{array}$ & $\begin{array}{l}0.6[60 \%] \\
0.3[30 \%] \\
0.1[10 \%]\end{array}$ \\
\hline
\end{tabular}

Table 2. Information about symptoms experienced and pharmacological treatment followed.

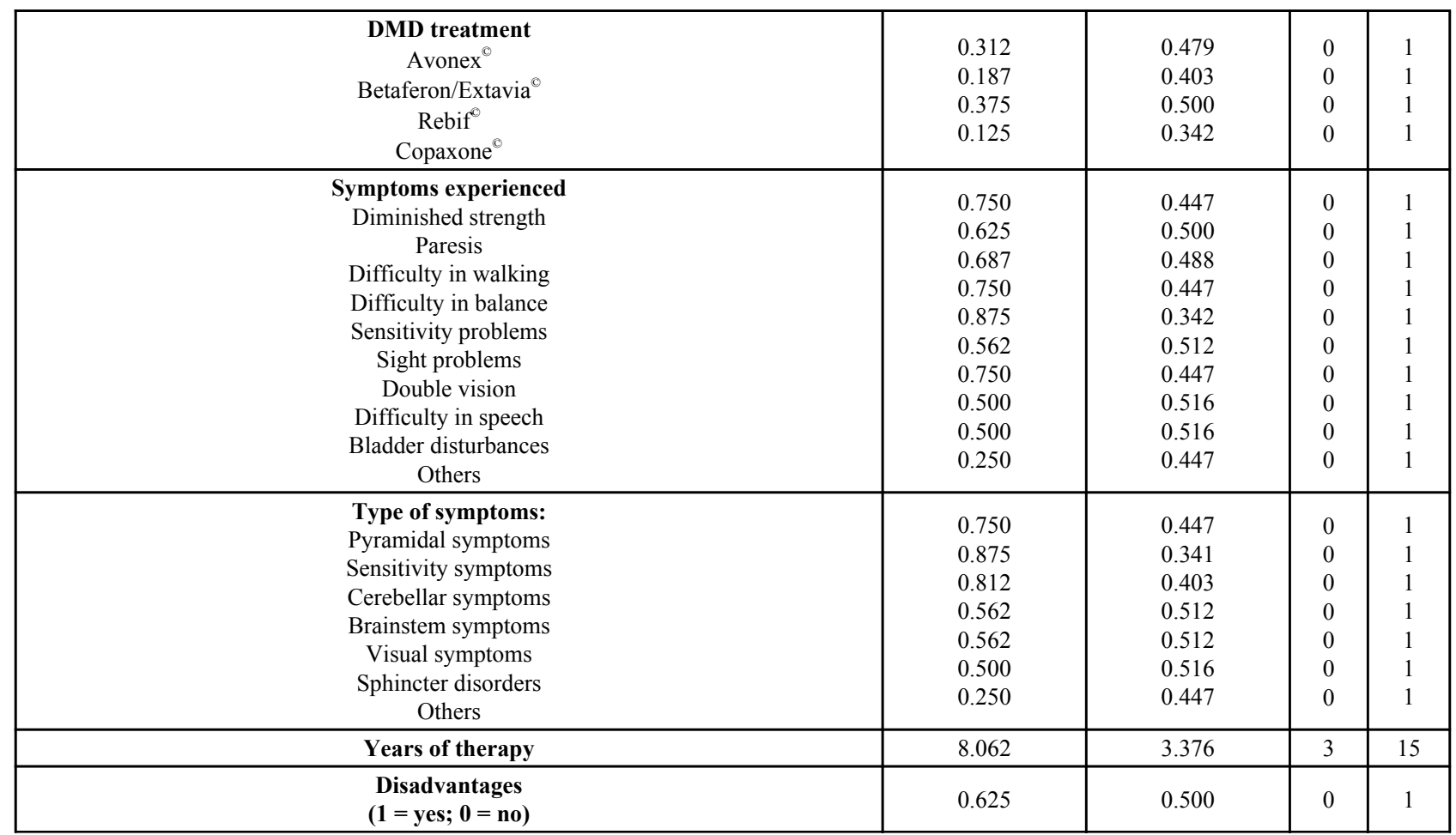


(Table 2) contd.....

\begin{tabular}{|c|c|c|c|c|}
\hline $\begin{array}{c}\text { Side effects } \\
(1=\text { yes } ; 0=\text { no })\end{array}$ & 0.937 & 0.250 & 0 & 1 \\
\hline Other drugs to contrast side effects & 0.562 & 0.512 & 0 & 5 \\
\hline
\end{tabular}

Table 3. Relapses experienced.

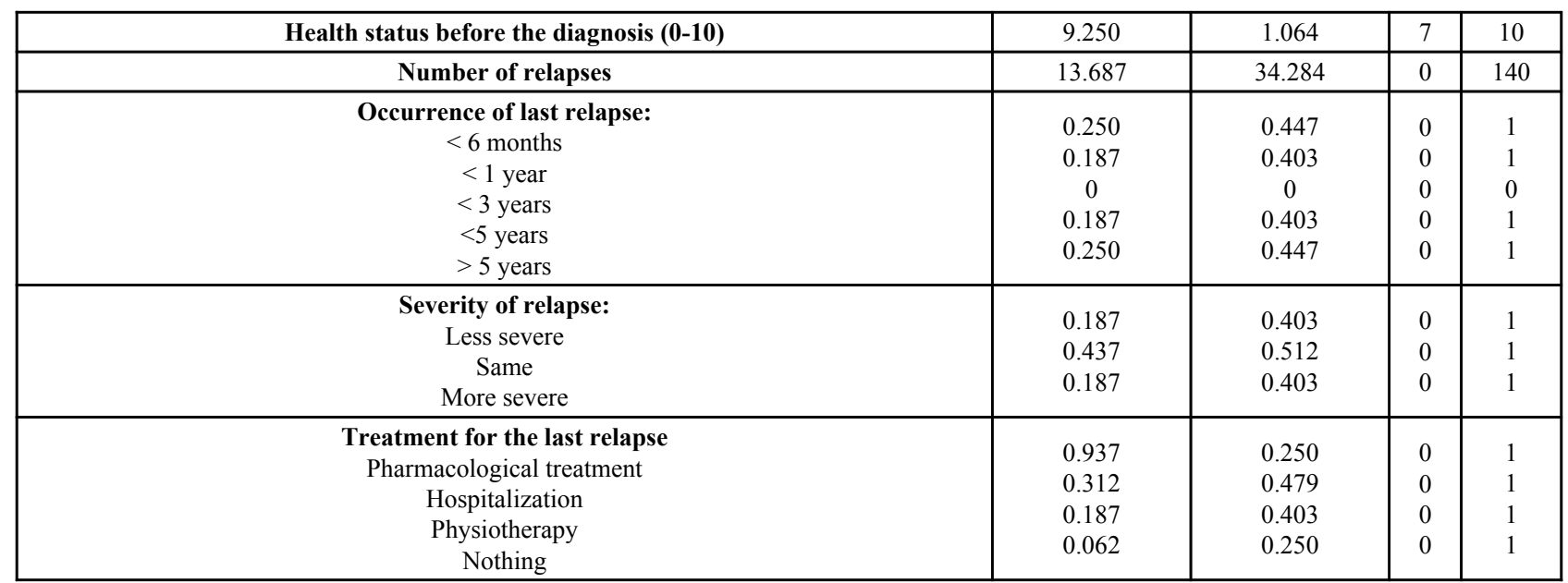

Table 4. Assessment of severity of symptoms, awareness of disease and treatment administration.

\begin{tabular}{|c|c|c|c|c|}
\hline $\begin{array}{c}\text { Variation in symptoms of disease } \\
\text { (1=not present anymore; } \mathbf{2}=\text { less present; } \mathbf{3}=\text { unchanged; } \mathbf{4}=\text { worsened): } \\
\text { Diminished strength } \\
\text { Paresis } \\
\text { Difficulty in walking } \\
\text { Difficulty in balance } \\
\text { Sensitivity problems } \\
\text { Sight problems } \\
\text { Double vision } \\
\text { Difficulty in speech } \\
\text { Bladder disturbances } \\
\text { Other } \\
\end{array}$ & $\begin{array}{l}1.812 \\
1.312 \\
1.812 \\
1.875 \\
2.125 \\
1.187 \\
1.625 \\
1.437 \\
1.562 \\
0.437\end{array}$ & $\begin{array}{l}1.558 \\
1.302 \\
1.559 \\
1.360 \\
1.360 \\
1.377 \\
1.408 \\
1.750 \\
1.711 \\
1.209\end{array}$ & $\begin{array}{l}0 \\
0 \\
0 \\
0 \\
0 \\
0 \\
0 \\
0 \\
0 \\
0\end{array}$ & $\begin{array}{l}4 \\
4 \\
4 \\
4 \\
4 \\
4 \\
4 \\
4 \\
4 \\
4 \\
4\end{array}$ \\
\hline $\begin{array}{l}\text { Variations in type of symptoms: } \\
\text { (1=not present anymore; } 2=\text { less present; } \mathbf{3}=\text { unchanged; } \mathbf{4}=\text { worsened): } \\
\text { Pyramidal symptoms } \\
\text { Sensitivity symptoms } \\
\text { Cerebellar symptoms } \\
\text { Brainstem symptoms } \\
\text { Visual symptoms } \\
\text { Sphincter disorders } \\
\text { Other }\end{array}$ & $\begin{array}{l}1.750 \\
2.125 \\
2.187 \\
1.625 \\
1.187 \\
1.562 \\
0.437\end{array}$ & $\begin{array}{l}1.438 \\
1.360 \\
1.424 \\
1.408 \\
1.377 \\
1.711 \\
1.209\end{array}$ & $\begin{array}{l}0 \\
0 \\
0 \\
0 \\
0 \\
0 \\
0\end{array}$ & $\begin{array}{l}4 \\
4 \\
4 \\
4 \\
4 \\
4 \\
4\end{array}$ \\
\hline Knowledge of disease ( 0 =diminished; $1=$ unchanged; $2=$ =increased $)$ & 1.75 & 0.683 & 0 & 2 \\
\hline $\begin{array}{l}\text { Source of information: } \\
\text { Physicians } \\
\text { Newspapers, tv, etc. } \\
\text { Other patients } \\
\text { Other }\end{array}$ & $\begin{array}{l}0.562 \\
0.750 \\
0.062 \\
0.625\end{array}$ & $\begin{array}{l}0.512 \\
0.447 \\
0.250 \\
0.250\end{array}$ & $\begin{array}{l}0 \\
0 \\
0 \\
0\end{array}$ & $\begin{array}{l}1 \\
1 \\
1 \\
1\end{array}$ \\
\hline Awareness of disease $(0=$ =worsened; 1 =unchanged; 2 =improved $)$ & 1.5 & 0.650 & 0 & 2 \\
\hline Is the treatment beneficial? $(1=$ yes $)$ & 0.937 & 0.250 & 0 & 1 \\
\hline $\begin{array}{l}\text { Assessment of side effects (on a scale from } 0 \text { to } 5 \text { - maximum disadvantage): } \\
\text { Flu-like symptoms } \\
\text { Pain in the site of injection } \\
\text { Mental/mood changes } \\
\text { Fatigue } \\
\text { Insomnia } \\
\text { Anemia } \\
\text { Thyroiditis } \\
\text { Other }\end{array}$ & $\begin{array}{l}0.256 \\
1.750 \\
1.437 \\
3.062 \\
1.687 \\
0.625 \\
0.500 \\
0.937\end{array}$ & $\begin{array}{l}1.590 \\
1.527 \\
1.896 \\
2.144 \\
1.778 \\
1.543 \\
1.414 \\
1.879\end{array}$ & $\begin{array}{l}0 \\
0 \\
0 \\
0 \\
0 \\
0 \\
0 \\
0\end{array}$ & 5 \\
\hline
\end{tabular}


(Table 4) contd.....

\begin{tabular}{|c|c|c|c|c|}
\hline Assessment of treatment advantages ( $1=$ low; $5=$ highest benefit $)$ & 3.812 & 1.682 & 0 & 5 \\
\hline $\begin{array}{l}\text { Assessment of treatment administration }(1=\text { no disadvantage; } 5=\text { max } \\
\text { disadvantage })\end{array}$ & 3.375 & 1.455 & 1 & 5 \\
\hline Interruptions of treatment ( $1=$ yes $)$ & 0.25 & 0.447 & 0 & 1 \\
\hline How many interruptions? & 0.50 & 1.095 & 0 & 4 \\
\hline Knowledge of new therapies & 0.437 & 0.512 & 0 & 1 \\
\hline $\begin{array}{l}\text { Fears about the future }(1=\text { fears of generic worsening; } 2=\text { fears of increased } \\
\text { limitations })\end{array}$ & 1.375 & 0.500 & 1 & 2 \\
\hline Risk of worsening (lower limit) & 26.666 & 19.148 & 0 & 50 \\
\hline Risk of worsening (upper limit) & 57.333 & 29.391 & 10 & 100 \\
\hline
\end{tabular}

It has been observed how some symptoms are more likely to have registered a worsening (such as sensitivity problems sensory functional systems symptoms are considered among the most invalidating consequences of MS - as well as difficulty in maintaining balance and walk); other symptoms are perceived to impact less in the long term, such as visual problems, which are more frequently reported at the disease onset (in fact, optic neuritis is often seen as an early sign for multiple sclerosis [39]). While the pharmacological treatment is thought to be beneficial according to the judgment expressed by patients (assessment of 3.812 on a scale from 1 to 5 ), the administration of the drug is often uncomfortable ( 3.375 on a scale from 1 to 5 , where 1 corresponds to the lowest disadvantage and 5 is the maximum). This could cause an interruption of the treatment ( $25 \%$ of patients declared to have stopped the treatment at least once, especially because the administration was difficult and/or painful).

Overall patients feel they increased their knowledge of the disease and in many cases $(56.2 \%)$ the physicians contributed to their improved awareness. Newspapers, TV, Internet, etc. have a leading role, representing $75 \%$ of the sources of information.

Patients suffering from MS for a long time are more worried about increased limitations in their daily life rather than a generic worsening of the disease (mean value of 1.375 , on a scale from 1 to 2 ).

While a minimum worsening of the disease ranging from 0 to 50 is expected, at least 3 patients think that they would experience a more severe course of the disease, quantifiable from 90 to 100 on a $0-100$ scale.

A correlation analysis has been carried out between the variables that may be crucial in determining compliance (years of treatment, symptoms experienced, severity of the relapses, information acquired about the disease) [40].

Table 2 show pairwise correlations, outlining the significant ones.

The Pearson correlation coefficient, $r$, that has been calculated, shows the strength and direction of the association between two variables. From the coefficient of correlation you

\footnotetext{
${ }^{2}$ For example, in Table 5a, the correlation coefficient between the years of disease and the years of therapy is 0.894 . Squaring this coefficient gives the coefficient of determination of 0.799 , which tells us that the number of years with disease is associated to positive number of years of therapy at $79.9 \%$ in percentage terms. This result, however, represents a statistical relationship, not just a casual relationship (for basic explanation, cfr. https://statistics.laerd.com/ stata-tutorials/pearsons-correlation-using-stata.php).
}

can obtain the coefficient of determination, i.e. the proportion of variance in one variable "explained" by the other variable correlated and calculated as the square of the correlation coefficient $\left(r^{2}\right)^{2}$.

Correlation coefficients between 0.1 and 0.3 show a small correlation; a medium/moderate correlation is associated to values of the coefficients between 0.3 and 0.5 ; large correlations are indicated by coefficients $>0.5$. Therefore, looking at Table $\mathbf{2}$, there is a high correlation between the years of disease and the years of therapy.

Pearson's coefficient $r$ is sensitive to outliers, which can have a very large effect on the line of best fit. Therefore, it is preferable not to have any outliers or interpreting cautiously the correlations between variables with outliers.

In the present case study, two variables present some outliers: the distance between the place of residence and the neurological center (that is of $219 \mathrm{~km}$ for one patient), and the number of relapses (one patient said to have experienced 140 relapses since the disease onset). Tables $\mathbf{5 a}$ and $\mathbf{5 b}$ report all the significant correlations.

Looking at each variable, the age of the patients is correlated with difficulties in following the therapy, as well as with a greater probability of not being compliant.

An inverse and significant correlation is also identified with age and a greater degree of awareness about the disease $(-0.356)$, while the correlation is positive and significant with the knowledge of the new therapies $(0.236)$. The results is surprising, as it seems that older patients claim not to be involved and not to look for more information about the course of disease, while at the same time trying to be informed about innovative treatment.

Women seem to complain less about the side effects related to drug treatment (inverse and significant correlation, -0.200 -, with disadvantages due to the treatment and with side effects $-0.333-$ ), while the distance from the neurological center is inversely and significantly correlated with the circumstance of being compliant $(-0.245)$, probably because of the greater discomfort for the patient, who has to travel, even after many years, to undergo the control visits or to take the drug.

The fact of being married adds more anxiety and concern $(0.333)$ and reduces the degree of awareness about the disease $(-0.504)$. The years of illness are significantly correlated with the years of therapy: evidently the patients started the treatment shortly after the diagnosis, as it had been seen in the first study [16]. 
Table 5a. Correlation analysis (1).

\begin{tabular}{|c|c|c|c|c|c|c|c|c|c|c|c|c|c|c|c|c|c|c|c|c|}
\hline Variable & Age & gender & Distance & \begin{tabular}{|c|} 
Primary \\
sch.
\end{tabular} & \begin{tabular}{|c|}
$\begin{array}{c}\text { High } \\
\text { school }\end{array}$ \\
\end{tabular} & Graduate & Married & \begin{tabular}{|c|} 
Income \\
2
\end{tabular} & \begin{tabular}{|c|} 
Income \\
3
\end{tabular} & avonex & Rebif & Betaf/ext & Copaxone & \begin{tabular}{|c|}
$\begin{array}{c}\text { Years } \\
\text { dis }\end{array}$ \\
\end{tabular} & Relapses & \begin{tabular}{|c|}
$>$ \\
severe
\end{tabular} & \begin{tabular}{|c|}
$=$ \\
severe
\end{tabular} & \begin{tabular}{|c|}
$<$ \\
severe \\
\end{tabular} & \begin{tabular}{|c|}
+5 \\
years
\end{tabular} & $\begin{array}{l}\begin{array}{l}\text { Years } \\
\text { ther }\end{array} \\
\end{array}$ \\
\hline Age & 1 & & & & & & & & & & & & & & & & & & & \\
\hline Gender & $0.234 *$ & 1 & & & & & & & & & & & & & & & & & & \\
\hline Distance & 0.006 & $\mid-0.020$ & 1 & & & & & & & & & & & & & & & & & \\
\hline $\begin{array}{c}\text { Primary } \\
\text { school }\end{array}$ & $0.446^{*}$ & $|-0.522 *|$ & 0.043 & 1 & & & & & & & & & & & & & & & & \\
\hline High school & -0.290 & $0.358^{*}$ & 0.097 & $-0.595^{*}$ & 1 & & & & & & & & & & & & & & & \\
\hline Graduate & -0.145 & 0.149 & -0.158 & \begin{tabular}{|l|}
$-0.389 *$ \\
\end{tabular} & $-0.509 *$ & 1 & & & & & & & & & & & & & & \\
\hline Married & 0.154 & 0.067 & \begin{tabular}{|l|}
$-0.428^{*}$ \\
\end{tabular} & $0.248^{*}$ & \begin{tabular}{|l|}
-0.098 \\
\end{tabular} & -0.149 & 1 & & & & & & & & & & & & & \\
\hline Income 2 & $-0.234^{*}$ & \begin{tabular}{|l|}
-0.067 \\
\end{tabular} & 0.044 & -0.244 & $0.358 *$ & -0.149 & $-0.467^{*}$ & 1 & & & & & & & & & & & & \\
\hline Income 3 & 0.045 & -0.067 & \begin{tabular}{|c|}
$-0.466^{*}$ \\
\end{tabular} & 0.035 & \begin{tabular}{|l|}
-0.163 \\
\end{tabular} & 0.149 & \begin{tabular}{|l|}
$0.333^{*}$ \\
\end{tabular} & $-0.600^{*}$ & 1 & & & & & & & & & & & \\
\hline Avonex & 0.174 & $-0.244 *$ & -0.010 & $0.418^{*}$ & $-0.323^{*}$ & -0.078 & -0.035 & 0.035 & $-0.244 *$ & 1 & & & & & & & & & & \\
\hline Rebif & $-0.214 *$ & $0.200^{*}$ & $-0.283^{*}$ & $-0.244 *$ & $0.358 *$ & -0.149 & 0.067 & $0.200^{*}$ & -0.067 & $-0.522 *$ & 1 & & & & & & & & & \\
\hline Betaf/ext & -0.083 & \begin{tabular}{|l|}
-0.041 \\
\end{tabular} & $0.474 *$ & \begin{tabular}{|l|}
$-0.324 *$ \\
\end{tabular} & $0.222 *$ & 0.092 & $-0.289^{*}$ & -0.041 & -0.041 & $-0.324 *$ & \begin{tabular}{|l|}
$-0.372^{*}$ \\
\end{tabular} & 1 & & & & & & & & \\
\hline Copaxone & 0.168 & 0.098 & -0.132 & 0.153 & $\mid-0.333 *$ & $0.218^{*}$ & $0.293^{*}$ & $-0.293 *$ & $0.488^{*}$ & $-0.255^{*}$ & \begin{tabular}{|l|}
$-0.293^{\prime}$ \\
\end{tabular} & -0.182 & 1 & & & & & & & \\
\hline Years dis & $0.189 *$ & \begin{tabular}{|l|}
-0.039 \\
\end{tabular} & 0.053 & -0.105 & $-0.245^{*}$ & $0.393 *$ & -0.030 & $-0.210^{*}$ & $0.236^{*}$ & 0.074 & \begin{tabular}{|l|}
$-0.519^{*}$ \\
\end{tabular} & $0.572 *$ & -0.019 & 1 & & & & & & \\
\hline Relapses & 0.033 & $-0.265 *$ & 0.004 & -0.067 & 0.194* & -0.151 & $0.207 *$ & $0.322 *$ & -0.164 & -0.160 & \begin{tabular}{|l|}
$0.276^{*}$ \\
\end{tabular} & -0.164 & 0.015 & -0.110 & 1 & & & & & \\
\hline$>$ Severe & $0.387 *$ & \begin{tabular}{|l|}
-0.041 \\
\end{tabular} & -0.178 & 0.022 & \begin{tabular}{|l|}
-0.101 \\
\end{tabular} & 0.092 & 0.041 & -0.041 & $0.289 *$ & 0.022 & \begin{tabular}{|l|l|}
$-0.372 *$ \\
\end{tabular} & 0.179 & $0.303^{*}$ & $0.529 *$ & -0.034 & 1 & & & & \\
\hline$=$ Severe & $-0.192 *$ & $-0.423 *$ & 0.080 & -0.051 & \begin{tabular}{|l|}
-0.016 \\
\end{tabular} & 0.073 & -0.098 & 0.098 & 0.098 & \begin{tabular}{|l|}
-0.051 \\
\end{tabular} & 0.098 & -0.101 & 0.048 & \begin{tabular}{|l|}
-0.144 \\
\end{tabular} & $0.304 *$ & $-0.424 *$ & 1 & & & \\
\hline$<$ Severe & $0.239 *$ & $0.289 *$ & -0.162 & 0.022 & \begin{tabular}{|l|}
-0.101 \\
\end{tabular} & 0.092 & $0.372 *$ & -0.041 & $-0.372 *$ & 0.022 & $0.289 *$ & $-0.231 *$ & -0.182 & $-0.194 *$ & -0.155 & $-0.231 *$ & $-0.424 *$ & 1 & & \\
\hline+5 years & \begin{tabular}{|l|}
0.033 \\
\end{tabular} & 0.149 & $0.299 *$ & \begin{tabular}{|l|}
$-0.389 *$ \\
\end{tabular} & \begin{tabular}{|l|}
0.073 \\
\end{tabular} & $0.033^{*}$ & -0.149 & -0.149 & -0.149 & -0.078 & \begin{tabular}{|l|l|}
$-0.447 *$ \\
\end{tabular} & $0.832^{*}$ & $-0.218^{*}$ & $0.662^{*}$ & \begin{tabular}{|l|}
$-0.199 *$ \\
\end{tabular} & \begin{tabular}{|l|}
0.092 \\
\end{tabular} & $-0.218^{*}$ & 0.092 & 1 & \\
\hline $\begin{array}{l}\text { Years of } \\
\text { therapy }\end{array}$ & 0.109 & $-0.133 \mid$ & 0.169 & .137 & -0.055 & $0.210^{*}$ & -0.143 & 0.094 & 0.143 & $-0.054 \mid$ & $-0.0331 *$ & $726^{*}$ & $.296^{*}$ & $0.894 *$ & -0.008 & $0.481^{*}$ & $\left|-0.210^{*}\right|$ & $\left|-0.205^{*}\right|$ & $0.651^{*}$ & 1 \\
\hline Disadvantages & $0.554 *$ & $-0.200 *$ & 0.110 & $0.244 *$ & \begin{tabular}{|l|}
-0.100 \\
\end{tabular} & -0.149 & -0.067 & $-0.200 *$ & 0.067 & $0.244 *$ & 0.067 & $-0.289^{*}$ & -0.098 & -0.167 & $0.226^{*}$ & $-0.289 *$ & 0.163 & 0.041 & -0.149 & $-0.183^{*}$ \\
\hline Side effects & \begin{tabular}{|l|}
0.045 \\
\end{tabular} & $-0.333 *$ & 0.141 & 0.174 & \begin{tabular}{|l|}
$0.228 *$ \\
\end{tabular} & $-0.447^{*}$ & \begin{tabular}{|l|}
$-0.200^{*}$ \\
\end{tabular} & $0.200^{*}$ & $-0.333 *$ & 0.174 & $0.200 *$ & 0.124 & $-0.683 *$ & \begin{tabular}{|l|}
-0.056 \\
\end{tabular} & 0.029 & $-0.537 *$ & $0.228^{*}$ & 0.124 & 0.149 & 0.084 \\
\hline Other drug & $0.212^{*}$ & $-0.358 *$ & 0.133 & $0.323 *$ & \begin{tabular}{|l|}
$0.270 *$ \\
\end{tabular} & $-0.655^{*}$ & $0.358^{*}$ & 0.163 & -0.098 & $0.323 *$ & 0.163 & $-0.222 *$ & $-0.429 *$ & $-0.190 *$ & $0.212 *$ & 0.101 & 0.016 & -0.101 & $-0.364 *$ & 0.017 \\
\hline Non compl & $0.234 *$ & -0.149 & $-0.245^{*}$ & $0.233 *$ & $-0.509 *$ & $0.333^{*}$ & -0.149 & -0.149 & 0.149 & $0.545^{*}$ & -0.149 & -0.277* & $-0.218^{*}$ & $0.355^{*}$ & -0.121 & 0.092 & $-0.218^{*}$ & 0.092 & 0.000 & $0.254^{*}$ \\
\hline How many & -0.055 & -0.243 & \begin{tabular}{|l|}
$-0.205^{*}$ \\
\end{tabular} & 0.064 & \begin{tabular}{|l|}
$-0.416 *$ \\
\end{tabular} & $0.408^{*}$ & \begin{tabular}{|l|}
$-0.243^{*}$ \\
\end{tabular} & $-0.243^{*}$ & $0.365^{*}$ & $0.191 *$ & 0.122 & $-0.226^{*}$ & -0.178 & 0.180 & -0.120 & -0.075 & \begin{tabular}{|l|}
0.059 \\
\end{tabular} & 0.076 & -0.136 & 0.171 \\
\hline Pyramid & $0.481^{*}$ & $-0.315 *$ & -0.128 & $0.305^{*}$ & \begin{tabular}{|l|}
$-0.285 *$ \\
\end{tabular} & 0.000 & 0.404* & 0.045 & $-0.225^{*}$ & -0.070 & $0.225 *$ & $-0.251 *$ & 0.066 & 0.032 & $0.489 *$ & 0.084 & \begin{tabular}{|l|}
-0.022 \\
\end{tabular} & $0.530 *$ & -0.100 & -0.037 \\
\hline Sensit & $0.446 *$ & $-0.368 *$ & 0.032 & $0.345^{*}$ & -0.179 & -0.164 & $0.368^{*}$ & -0.073 & 0.024 & $\mid-0.269 *$ & $0.319^{*}$ & $-0.289^{*}$ & $0.251^{*}$ & -0.118 & $0.473^{*}$ & 0.076 & $0.299^{*}$ & $0.198^{*}$ & $-0.384 *$ & -0.147 \\
\hline Cerebel & $0.284 *$ & $-0.199 *$ & 0.049 & 0.104 & \begin{tabular}{|l|}
$-0.211 *$ \\
\end{tabular} & 0.131 & $0.199 *$ & $-0.199 *$ & 0.175 & $-0.287 *$ & 0.175 & 0.051 & 0.086 & \begin{tabular}{|l|}
0.174 \\
\end{tabular} & $0.373^{*}$ & -0.181 & -0.028 & $0.283^{*}$ & 0.131 & 0.178 \\
\hline Brainstem & $0.267^{*}$ & \begin{tabular}{|l|}
$-0.260 *$ \\
\end{tabular} & \begin{tabular}{|l|}
$-0.192^{*}$ \\
\end{tabular} & $0.284^{*}$ & \begin{tabular}{|l|}
0.058 \\
\end{tabular} & $-0.370^{*}$ & 0.0544* & -0.071 & 0.118 & $-0.507 *$ & 0.402 & -0.103 & $0.242^{*}$ & $-0.206^{*}$ & $0.325^{*}$ & 0.015 & \begin{tabular}{|l|}
0.150 \\
\end{tabular} & $0.249^{*}$ & $-0.265 *$ & \begin{tabular}{|l|}
-0.163 \\
\end{tabular} \\
\hline Visual & $0.200^{*}$ & $-0.303 *$ & \begin{tabular}{|l|}
-0.027 \\
\end{tabular} & 0.107 & 0.159 & $-0.298^{*}$ & \begin{tabular}{|l|}
$0.399^{*}$ \\
\end{tabular} & 0.182 & $-0.399 *$ & -0.095 & $0.278^{*}$ & 0.052 & $-0.337 *$ & -0.132 & $0.335^{*}$ & 0.052 & -0.124 & $0.533^{*}$ & 0.027 & 0.054 \\
\hline Sphinct & $0.256^{*}$ & -0.730 & 0.006 & $0.259^{*}$ & \begin{tabular}{|l|}
-0.223 \\
\end{tabular} & -0.022 & 0.029 & -0.029 & 0.049 & -0.147 & 0.127 & 0.127 & -0.128 & $0.244^{*}$ & $0.450^{*}$ & $0.223^{*}$ & $0.309^{*}$ & -0.163 & -0.022 & $0.328^{*}$ \\
\hline Other & -0.007 & $-0.029 *$ & \begin{tabular}{|l|}
$-0.241^{*}$ \\
\end{tabular} & \begin{tabular}{|l|}
$-0.252^{*}$ \\
\end{tabular} & \begin{tabular}{|l|}
0.101 \\
\end{tabular} & 0.154 & -0.041 & $-0.289^{*}$ & 0.482 & $0.252 *$ & 0.041 & $0.367^{*}$ & -0.131 & $0.421^{*}$ & -0.104 & $0.367^{*}$ & -0.007 & -0.179 & $0.277^{*}$ & 0.499* \\
\hline Knowl MS & $-0.402 *$ & -0.098 & \begin{tabular}{|l|}
$-0.663^{*}$ \\
\end{tabular} & -0.153 & \begin{tabular}{|l|}
-0.048 \\
\end{tabular} & $0.218^{*}$ & $0.488^{*}$ & -0.098 & $0.293^{*}$ & -0.153 & 0.293* & $-0.303^{*}$ & 0.143 & $-0.333^{*}$ & 0.042 & $-0.303 *$ & $0.333^{*}$ & 0.182 & $-0.218^{*}$ & $-0.397 *$ \\
\hline Physicians & -0.022 & 0.163 & \begin{tabular}{|l|}
$-0.379^{*}$ \\
\end{tabular} & 0.051 & 0.016 & -0.073 & $0.618^{*}$ & $-0.358^{*}$ & $0.423^{*}$ & $0.329 *$ & \begin{tabular}{|l|}
$-0.358^{*}$ \\
\end{tabular} & $-0.222^{*}$ & $0.333^{*}$ & 0.044 & $-0.297^{*}$ & \begin{tabular}{|l|}
0.101 \\
\end{tabular} & 0.016 & 0.101 & -0.073 & -0.176 \\
\hline Tv, internet & $-0.413^{*}$ & 0.149 & \begin{tabular}{|l|}
$-0.646^{*}$ \\
\end{tabular} & \begin{tabular}{|l|}
$-0.545^{*}$ \\
\end{tabular} & |0.218* & $0.333^{*}$ & 0.149 & 0.149 & $0.447^{*}$ & $-0.233 *$ & 0.149 & -0.092 & $0.218^{*}$ & -0.010 & 0.099 & -0.092 & \begin{tabular}{|l|}
$0.218^{*}$ \\
\end{tabular} & -0.092 & 0.000 & -0.121 \\
\hline Patients & $0.434 *$ & -0.200 & 0.004 & $0.383 *$ & $-0.228^{*}$ & -0.149 & $0.200^{*}$ & $-0.200 *$ & $-0.200 *$ & 0.174 & $0.333^{*}$ & -0.124 & -0.098 & $-0.425 *$ & -0.060 & -0.124 & $-0.228^{*}$ & $0.537^{*}$ & -0.149 & $-0.242^{*}$ \\
\hline Other & $0.274 *$ & $-0.200 *$ & -0.039 & $0.383 *$ & \begin{tabular}{|l|}
$-0.228^{*}$ \\
\end{tabular} & -0.149 & $0.200^{*}$ & $-0.200^{*}$ & $0.333^{*}$ & 0.174 & \begin{tabular}{|l|}
$-0.200^{*}$ \\
\end{tabular} & -0.124 & $0.683^{*}$ & -0.081 & 0.049 & -0.124 & $0.293 *$ & -0.124 & -0.149 & $-0.321 *$ \\
\hline$>$ Aware & $-0.356^{*}$ & -0.119 & $0.221 *$ & $-0.252 *$ & $0.230 *$ & 0.000 & \begin{tabular}{|l|}
$-0.504 *$ \\
\end{tabular} & $0.357^{*}$ & $-0.461 *$ & $0.252 *$ & 0.000 & $0.326^{*}$ & $-0.651^{*}$ & 0.152 & $-0.283^{*}$ & $-0.326^{*}$ & 0.114 & 0.139 & 0.417* & $-0.214^{*}$ \\
\hline$>$ Worrie & 0.125 & $-0.333 *$ & -0.142 & 0.035 & -0.163 & 0.149 & $0.333^{*}$ & $-0.333^{*}$ & -0.067 & 0.035 & $0.200^{*}$ & -0.041 & -0.293* & 0.099 & $0.314 *$ & -0.042 & 0.098 & $0.289^{*}$ & 0.149 & 0.104 \\
\hline New ther & $0.236^{*}$ & -0.163 & 0.134 & $0.221 *$ & $-0.270^{*} \mid$ & 0.073 & 0.163 & $-0.423 *$ & 0.098 & -0.051 & 0.098 & -0.101 & 0.048 & -0.111 & $0.293^{*}$ & $-0.424 *$ & -0.016 & $0.222 *$ & 0.073 & -0.132 \\
\hline
\end{tabular}

Table 5b. Correlation analysis (2).

\begin{tabular}{|c|c|c|c|c|c|c|c|c|c|c|c|c|c|c|c|c|c|c|c|c|}
\hline Disadvantage & \begin{tabular}{|c|} 
Side \\
effects
\end{tabular} & $\begin{array}{l}\text { Other } \\
\text { drug }\end{array}$ & \begin{tabular}{|c|}
$\begin{array}{c}\text { Non } \\
\text { compl }\end{array}$ \\
\end{tabular} & $\begin{array}{l}\text { How } \\
\text { many }\end{array}$ & Pyramid & Sensit & cerebel & brainstem & visual & sphincter & Other & $\begin{array}{c}\text { Knowl } \\
\text { MS }\end{array}$ & Physic & \begin{tabular}{|c|} 
Tv, \\
internet
\end{tabular} & Patients & other & $\begin{array}{c}> \\
\text { awaren }\end{array}$ & \begin{tabular}{|c|}
$>$ \\
worries \\
\end{tabular} & \begin{tabular}{|l|} 
New \\
ther
\end{tabular} & \\
\hline & & & & & & & & & & & & & & & & & & & & Age \\
\hline & & & & & & & & & & & & & & & & & & & & Gender \\
\hline & & & & & & & & & & & & & & & & & & & & Distance \\
\hline & & & & & & & & & & & & & & & & & & & & $\begin{array}{c}\text { Primary } \\
\text { school }\end{array}$ \\
\hline & & & & & & & & & & & & & & & & & & & & High school \\
\hline & & & & & & & & & & & & & & & & & & & & Graduate \\
\hline & & & & & & & & & & & & & & & & & & & & Married \\
\hline & & & & & & & & & & & & & & & & & & & & Income 2 \\
\hline & & & & & & & & & & & & & & & & & & & & Income 3 \\
\hline & & & & & & & & & & & & & & & & & & & & Avonex \\
\hline & & & & & & & & & & & & & & & & & & & & Rebif \\
\hline & & & & & & & & & & & & & & & & & & & & Betaf/ext \\
\hline & & & & & & & & & & & & & & & & & & & & Copaxone \\
\hline & & & & & & & & & & & & & & & & & & & & Years dis \\
\hline & & & & & & & & & & & & & & & & & & & & Relapses \\
\hline & & & & & & & & & & & & & & & & & & & & $>$ Severe \\
\hline & & & & & & & & & & & & & & & & & & & & $=$ Severe \\
\hline & & & & & & & & & & & & & & & & & & & & $<$ Severe \\
\hline & & & & & & & & & & & & & & & & & & & & +5 years \\
\hline & & & & & & & & & & & & & & & & & & & & $\begin{array}{l}\text { Years of } \\
\text { therapy }\end{array}$ \\
\hline 1 & & & & & & & & & & & & & & & & & & & & Disadvantages \\
\hline
\end{tabular}




\begin{tabular}{|c|c|c|c|c|c|c|c|c|c|c|c|c|c|c|c|c|c|c|c|c|}
\hline Disadvantage & \begin{tabular}{|c|} 
Side \\
effects
\end{tabular} & \begin{tabular}{|c|}
$\begin{array}{c}\text { Other } \\
\text { drug }\end{array}$ \\
\end{tabular} & \begin{tabular}{|c|} 
Non \\
compl
\end{tabular} & \begin{tabular}{|c|} 
How \\
many
\end{tabular} & Pyramid & Sensit & cerebel & brainstem & visual & sphincter & Other & \begin{tabular}{|c|} 
Knowl \\
MS
\end{tabular} & Physic & \begin{tabular}{|c|}
$\mathrm{Tv}$, \\
internet
\end{tabular} & Patients & other & \begin{tabular}{|c|} 
\\
awaren \\
\end{tabular} & $\begin{array}{c}> \\
\text { worries }\end{array}$ & \begin{tabular}{|l|} 
New \\
ther \\
\end{tabular} & \\
\hline $0.333^{*}$ & 1 & & & & & & & & & & & & & & & & & & & Side effects \\
\hline 0.098 & $0.293 *$ & 1 & & & & & & & & & & & & & & & & & & Other drug \\
\hline 0.447 & 0.149 & -0.073 & 1 & & & & & & & & & & & & & & & & & Non compl \\
\hline $0.365^{*}$ & 0.122 & \begin{tabular}{|l|}
-0.178 \\
\end{tabular} & $0.816^{*}$ & 1 & & & & & & & & & & & & & & & & How many \\
\hline 0.135 & 0.135 & 0.197* & \begin{tabular}{|l|}
0.100 \\
\end{tabular} & \begin{tabular}{|l|}
0.000 \\
\end{tabular} & 1 & & & & & & & & & & & & & & & Pyramid \\
\hline 0.172 & 0.024 & $0.275^{*}$ & \begin{tabular}{|l|}
-0.163 \\
\end{tabular} & \begin{tabular}{|l|}
-0.044 \\
\end{tabular} & \begin{tabular}{|l|}
$0.810^{*}$ \\
\end{tabular} & 1 & & & & & & & & & & & & & & Sensit \\
\hline $0.480^{*}$ & $0.222^{*}$ & \begin{tabular}{|l|}
-0.154 \\
\end{tabular} & $0.340^{*}$ & $0.406^{*}$ & \begin{tabular}{|l|}
$0.560^{*}$ \\
\end{tabular} & $0.434 *$ & 1 & & & & & & & & & & & & & Cerebel \\
\hline-0.118 & 0.118 & $0.312 *$ & $-0.476^{*}$ & $-0.346 * \mid$ & $|0.654 *|$ & $0.792 *$ & $0.303 *$ & 1 & & & & & & & & & & & & Brainstem \\
\hline-0.182 & $0.230^{*}$ & $0.596^{*}$ & $-0.298 *$ & $-0.331 *$ & \begin{tabular}{|l|}
$0.677^{*}$ \\
\end{tabular} & $0.521 *$ & 0.151 & $0.623^{*}$ & 1 & & & & & & & & & & & Visual \\
\hline 0.029 & $0.243 *$ & $0.223 *$ & \begin{tabular}{|l|}
0.065 \\
\end{tabular} & $0.231 *$ & \begin{tabular}{|l|}
$0.611^{*}$ \\
\end{tabular} & $0.655 *$ & $0.337^{*}$ & $0.508^{*}$ & $0.490^{*}$ & 1 & & & & & & & & & & Sphinct \\
\hline-0.152 & 0.096 & \begin{tabular}{|l|}
0.007 \\
\end{tabular} & 0.154 & 0.428 & 0.065 & \begin{tabular}{|l|}
0.086 \\
\end{tabular} & 0.181 & 0.142 & \begin{tabular}{|l|}
0.148 \\
\end{tabular} & $0.550^{*}$ & 1 & & & & & & & & & Other \\
\hline$-0.293^{*}$ & -0.098 & \begin{tabular}{|l|}
0.048 \\
\end{tabular} & $-0.218^{*}$ & 0.000 & 0.066 & 0.036 & -0.086 & $0.312^{*}$ & \begin{tabular}{|l|}
$0.195^{*}$ \\
\end{tabular} & 0.0143 & \begin{tabular}{|l|}
0.141 \\
\end{tabular} & 1 & & & & & & & & Knowl MS \\
\hline-0.163 & $-0.228 *$ & 0.237* & \begin{tabular}{|l|}
-0.073 \\
\end{tabular} & \begin{tabular}{|l|}
-0.178 \\
\end{tabular} & -0.153 & \begin{tabular}{|l|}
-0.108 \\
\end{tabular} & \begin{tabular}{|l|}
$-0.246 *$ \\
\end{tabular} & 0.035 & \begin{tabular}{|l|}
-0.065 \\
\end{tabular} & $-0.385^{*}$ & \begin{tabular}{|l|}
0.007 \\
\end{tabular} & $0.429 *$ & 1 & & & & & & & Physicians \\
\hline-0.149 & -0.149 & $-0.218^{*}$ & 0.000 & 0.136 & $|-0.201 *|$ & $-0.274 *$ & 0.078 & -0.053 & $-0.244 * \mid$ & $-0.239 *$ & $0.216^{*}$ & $0.655^{*}$ & $0.364 *$ & 1 & & & & & & Tv, internet \\
\hline $0.200^{*}$ & 0.067 & $0.228 *$ & \begin{tabular}{|l|}
-0.149 \\
\end{tabular} & \begin{tabular}{|l|}
-0.122 \\
\end{tabular} & \begin{tabular}{|l|}
$0.404 *$ \\
\end{tabular} & $0.368 *$ & 0.152 & $0.450^{*}$ & $0.545^{*}$ & $0.224 *$ & \begin{tabular}{|l|}
-0.096 \\
\end{tabular} & \begin{tabular}{|l|}
0.098 \\
\end{tabular} & $-0.293 *$ & \begin{tabular}{|l|}
$-0.447^{*}$ \\
\end{tabular} & 1 & & & & & Patients \\
\hline $0.200^{*}$ & 0.067 & $-0.293 *$ & \begin{tabular}{|l|}
-0.149 \\
\end{tabular} & \begin{tabular}{|l|}
-0.122 \\
\end{tabular} & \begin{tabular}{|l|}
$0.225^{*}$ \\
\end{tabular} & 0.368 & $0.339^{*}$ & $0.450^{*}$ & $-0.230 *$ & 0.068 & \begin{tabular}{|c|}
-0.096 \\
\end{tabular} & 0.098 & $0.228^{*}$ & 0.149 & \begin{tabular}{|l|}
-0.067 \\
\end{tabular} & 1 & & & & Other \\
\hline$-0.230^{*}$ & $0.664^{*}$ & \begin{tabular}{|l|}
0.000 \\
\end{tabular} & \begin{tabular}{|l|}
0.139 \\
\end{tabular} & \begin{tabular}{|l|}
0.153 \\
\end{tabular} & -0.040 & $-0.252 *$ & -0.156 & $-0.208^{*}$ & \begin{tabular}{|l|}
0.165 \\
\end{tabular} & 0.136 & $0.322 *$ & 0.000 & -0.119 & -0.000 & \begin{tabular}{|l|}
$-0.221 *$ \\
\end{tabular} & \begin{tabular}{|l|}
-0.221 \\
\end{tabular} & 1 & & & $>$ Aware \\
\hline 0.067 & \begin{tabular}{|l|}
$0.200^{*}$ \\
\end{tabular} & \begin{tabular}{|l|}
0.163 \\
\end{tabular} & \begin{tabular}{|l|}
0.149 \\
\end{tabular} & $0.243 *$ & \begin{tabular}{|l|}
$0.584^{*}$ \\
\end{tabular} & 0.417* & $0.269^{*}$ & $0.308^{*}$ & 0.569* & $0.672^{*}$ & $0.482^{*}$ & $0.293 *$ & -0.098 & 0.149 & \begin{tabular}{|l|}
$0.333 *$ \\
\end{tabular} & \begin{tabular}{|l|}
$-0.200^{*}$ \\
\end{tabular} & \begin{tabular}{|l|}
$0.230^{*}$ \\
\end{tabular} & 1 & & $>$ Worrie \\
\hline $0.683^{*}$ & $0.228^{*}$ & $-0.238 * \mid$ & $0.364^{*}$ & $0.416^{*}$ & $\left|0.329^{*}\right|$ & $0.203 *$ & $0.794 *$ & 0.058 & -0.029 & 0.157 & $|-0.007|$ & -0.048 & $-0.238^{*} \mid$ & -0.073 & 0.293* & $0.293^{*}$ & -0.230 & $0.358^{*}$ & 1 & New ther \\
\hline
\end{tabular}

The circumstance of having experienced some relapses increases the concerns about the disease $(0.314)$ but stimulates the patients' curiosity to deepen their knowledge of new therapies (0.293).

Among the DMDs, those that require a closer administration over time (for example, Betaferon $\%$ Extavia $^{\circ}$, with alternate-day administration (-0.277), or Copaxone ${ }^{\mathcal{O}}(-0.218)$, with daily administrations), compared to Rebif ${ }^{\circ} 22$ or 44 (3 administrations per week, correlation not significant 0.149 ) or $\operatorname{Avonex}^{\circ}(1$ weekly dose, 0.545$)$ are associated with a better compliance.

Among symptoms, classified according to functional systems, brainstem (encephalic trunk) disorders (-0.476) and visual disturbances $(-0.298)$ are inversely and significantly correlated with the circumstance of not being compliant (hence, with a higher compliance), while, on the contrary, cerebellar disorders show a positive and significant correlation (0.340).

The acquisition of a higher level of knowledge and awareness of the disease is associated with a lower probability of not being compliant (-0.218).

\section{DISCUSSION AND CONCLUSIONS}

Although the analysis was carried out on a very limited sample of patients, who had already responded to the first survey and who are still treated at the same neurological center, the resulting evidence demonstrates how a compliance attitude can be maintained in the long-term, even if a deterioration of health conditions is observed.

There is, of course a selection bias of the sample: the patients who answered the questionnaire have been compliant in the last two years, so the analysis cannot be regarded as a study of non compliance, rather, as a discussion on the factors that have fostered the compliance in the course of time.

In particular, two patterns of compliance might be identified and they are both linked with time from diagnosis and beginning of treatment.

There is a clear distinction between 1) new patients and 2) experienced patients.

New patients have just started to know the disease and its symptoms. They have been told to follow a pharmacological treatment with DMDs and are, obviously, anxious about the course of MS. However, the therapy is often seen as uncomfortable, given its side effects and, if the patient has completely overcome the relapse, he/she will not be willing to comply with the therapy.

Experienced patients, on the other hand, have a higher degree of awareness both of the disease and the therapy. If they have been compliant, they will continue to follow the neurologists' prescriptions. They might even assume a leading role in the relationship with the physicians, asking for information especially about inno-vative treatment.

Therefore, while helping new patients to reach compliance has to be seen as an objective for physicians and health personnel, compliance does not represent a challenge anymore for experienced patients. What should instead be fostered is their willingness to talk about themselves and to continue reporting variations in symptoms and satisfaction with the therapy.

The quality of information and the involvement of the same patient in the process of taking care of himself/ herself, for experienced patients moves towards a consolidation of the therapeutic alliance between doctor and patient.

Based on the answers given by patients who had sometimes not been compliant, the most frequent reasons for non compliance are the side effects related to treatment (such as flu-like symptoms) and the discomfort related to its administration. It has been stressed how anxiety and fears caused by the injections are quite common: learning how to inject with the minimum discomfort can help ease the anxiety (see, for example, http://www.healthcommunities.com/multiple -sclerosis/self-injection-ms-shot_bht.shtml).

Moreover, most of the drugs are now administered orally or through infusion and, unless there are factors that determine a contraindications for the patient (for example, the positivity to JCV for natalizumab [41], or an increased cardiac risk for 
fingolimod [42]) compliance can be improved too.

Other MS supporting treatments can be considered. First of all, psychotherapy should be a fundamental component of assistance programs: the central nervous system abnormalities associated with MS and the psychological and social impact of the disorder often result in mood swings and depression. MS support groups and counseling may be helpful.

Treatment for MS may also include physical therapy, occupational therapy, and speech therapy. Physical therapy uses exercises to help strengthen muscles, reduce pain and spasticity, and improve balance and walking. Occupational therapy increases independent function in activities of daily living and focus on dressing, eating, driving, and handwriting. Finally, speech therapy may be helpful if slurred speech (dysarthria) or difficulty swallowing (dysphagia) develops.

The analysis does not consider if and which pharmacological treatment switches occurred for the same sample. A question to include in a subsequent survey could be if the assessment of patient experience has remained the same in spite of switches.

Continuous education and consistent reinforcement of the value of treatment are essential strategies in the maintenance of treatment adherence [37].

To enrich the analysis that was carried out, the questionnaire could include some items specifically aimed at investigating quality of life and detecting how the latter can be affected by the pharmacological treatment that, in turn, impact on compliance. Maintaining motivation and treatment adherence in patients with MS is important for optimal wellbeing. With this objective in mind, patients and healthcare providers need to work together to establish open lines of communication and a trust-based therapeutic relationship to ensure that patients have the knowledge and skills they need to adhere to long-term MS therapy [37].

Patients' perspectives may help to draw guidelines to guarantee a qualitatively adequate assistance. In fact, patient satisfaction is of major importance in the implementation of the Customer Satisfaction Management model, as stressed by the European Primer on Customer Satisfaction Management [43].

Successful organizations use customers' expectations as the starting point: managing satisfaction has to do with services and/or products, but also with the ultimate satisfaction of the citizen/customer [43, 44].

\section{APPENDIX}

Avonex ${ }^{\circledR}$ is a once-a-week injectable treatment for relapsing MS. It has been prescribed to over 455,000 people since its approval in 1996. It can decrease the number of relapses, slow the progression of physical disability, as well as reducing brain lesions on magnetic resonance imaging (MRI). In people who took the drug for the full 2 years of a study, it reduced relapses by $32 \%$ compared with placebo (https://www.avonex.com).

Rebif $^{\circledR}$, in the formulations 22 and 44, was approved in Europe in 1998 and in the United States in 2002, and registered in more than 90 countries around the world for relapsing remitting MS.
Rebif is administerd by subcutaneous injection three times a week. The drug has been shown to delay the progression of disability, reduce the frequency of relapses and the activity and extent of neurological damage. A number oftudies have highlighted the long-term efficacy of the IFN- $\beta 1 \alpha$ [45 - 46].

Extavia $^{\circledR}$ and Betaferon ${ }^{\circledR}$ are MS treatments whose active ingredients is IFN- $\beta 1 \beta$, used to reduce the number of relapses in people with relapsing forms of MS; IFN- $\beta 1 \beta$ has been shown to decrease the number of new MRI lesions and reduce the size of existing MRI lesions. In patients who have had one episode and whose MRI findings are consistent with MS, Extavia ${ }^{\circledR}$ has been shown to reduce the risk of having a second clinical attack within 2 years (https://www.extavia.com; see also http://www.ema.europa.eu/docs/it_IT/document_library /EPAR_-_Summary_for_the_public/human/000081/WC5000 53086.pdf).

Copaxone $^{\circledR}$ (glatiramer acetate, GA) is thought to work by modifying the immune system and has to be administered by daily subcutaneous injection. The mechanisms by which GA exerts its effects in patients with MS are not fully understood. However, GA is thought to act by modifying immune processes that are believed to be responsible for the pathogenesis of MS [47 - 48].

\section{ETHICS APPROVAL AND CONSENT TO PARTICIPATE}

Not applicable.

\section{HUMAN AND ANIMAL RIGHTS}

No animals/humans were used for studies that are the basis of this research.

\section{CONSENT FOR PUBLICATION}

Written informed consent was obtained from all the participants prior to publication.

\section{CONFLICT OF INTEREST}

The editor declares no conflict of interest, financial or otherwise.

\section{ACKNOWLEDGEMENTS}

The author would like to thank health professionals at the Centro Studi Neurolesi "Bonino Pulejo" in Messina, (Italy), where the survey has been carried on: Lorenzo De Santi, Giovanni Polimeni and Eleonora Palella for clinical and pharmacological consultancy, as well as collaboration in collecting and organizing data. Usual disclaimers apply.

\section{REFERENCES}

[1] Kantarci OH, Weinshenker BG. Natural history of multiple sclerosis. Neurol Clin 2005; 23(1): 17-38

[http://dx.doi.org/10.1016/j.ncl.2004.10.002] [PMID: 1566 1086]

[2] Brody JE. From Multiple Sclerosis, a Multiplicity of Challenges. The New York Times Health 2008 March 4. Available from: http:// www.nytimes.com/ 2008/ 03/04/ health/ 04brod.html

[3] Noseworthy JH, Lucchinetti C, Rodriguez M, Weinshenker BG. Multiple sclerosis. N Engl J Med 2000; 343(13): 938-52. [http://dx.doi.org/10.1056/NEJM200009283431307] [PMID: 
[4] Shadday A, Cohan S. MS and your feelings: Handling the ups and downs of multiple sclerosis. Turner Publishing Company 2006.

[5] Burks JS, Bigley GK, Hill HH. Rehabilitation challenges in multiple sclerosis. Ann Indian Acad Neurol 2009; 12(4): 296-306. [http://dx.doi.org/10.4103/0972-2327.58273] [PMID: 2018 2578]

[6] IFN- $\beta$ Multiple sclerosis study group \& The university of british columbia MS/MRI analysis group. Interferon beta- $1 \mathrm{~b}$ in the treatment of multiple sclerosis: Final outcome of the randomized controlled trial. Neurology 1995; 45(7): 1277-85

[http://dx.doi.org/10.1212/WNL.45.7.1277] [PMID: 7617182]

[7] Panitch H, Goodin D, Francis G, et al. EVIDENCE (EVidence of Interferon Dose-response: European North American Comparative Efficacy) Study group and the university of british columbia MS/MRI research group. Benefits of high-dose, high-frequency interferon beta-1a in relapsing-remitting multiple sclerosis are sustained to 16 months: Final comparative results of the EVIDENCE trial. J Neurol Sci 2005; 239(1): 67-74.

[http://dx.doi.org/10.1016/j.jns.2005.08.003] [PMID: 161 69561]

[8] Jacobs LD, Cookfair DL, Rudick RA, et al. The Multiple Sclerosis Collaborative Research Group (MSCRG). Intramuscular interferon beta-1a for disease progression in relapsing multiple sclerosis. Ann Neurol 1996; 39(3): 285-94.

[http://dx.doi.org/10.1002/ana.410390304] [PMID: 8602746]

[9] Johnson KP. Control of multiple sclerosis relapses with immunomodulating agents. J Neurol Sci 2007; 256(Suppl. 1): S23-8. [http://dx.doi.org/10.1016/j.jns.2007.01.060] [PMID: 17350 652]

[10] Ransohoff RM. Natalizumab for multiple sclerosis. N Engl J Med 2007; 356(25): 2622-9.

[http://dx.doi.org/10.1056/NEJMct071462] [PMID: 17582072]

[11] Pelletier D, Hafler DA. Fingolimod for multiple sclerosis. N Engl J Med 2012; 366(4): 339-47.

[http://dx.doi.org/10.1056/NEJMct1101691] [PMID: 22276 823]

[12] Osmed. L'uso dei farmaci in Italia. Rapporto nazionale anno 2011. Available from: http://www.aifa.gov.it/sites/default/files/1_-_rapporto osmed 2011.pdf

[13] AISM. Barometro della sclerosi multipla 2017. Available from: https://welforum.it/wp-content/uploads/2017/06/Barometro_della_Scle rosi_Multipla_2017.pdf

[14] Miller JR. The importance of early diagnosis of multiple sclerosis. J Manag Care Pharm 2004; 10(3)(Suppl. B): S4-S11.

[PMID: 15253684]

[15] Gajofatto A, Benedetti MD. Treatment strategies for multiple sclerosis: When to start, when to change, when to stop? World J Clin Cases 2015; 3(7): 545-55.

[http://dx.doi.org/10.12998/wjcc.v3.i7.545] [PMID: 26244148]

[16] Gitto L. Multiple Sclerosis patients' awareness of disease and compliance to pharmacological treatment with Disease Modifying Drugs (DMDs). Eur J Pers Cent Healthc 2016; 4: 599-608.

[17] Kavaliunas A, Manouchehrinia A, Stawiarz L, et al. Importance of early treatment initiation in the clinical course of multiple sclerosis. Mult Scler 2017; 23(9): 1233-40.

[http://dx.doi.org/10.1177/1352458516675039] [PMID: 2775 4943]

[18] Devonshire V. Adherence to Disease-Modifying Therapy: Recognizing the Barriers and Offering Solutions. Ridgewood, NJ: Delaware Media Group, LLC 2007.

[19] Gonzalez JJ, Sawicka A. The role of learning and risk perception in compliance. Proceedings of the 21st International Conference System Dynamics Society New York. 2003.2003.

[20] O'Rourke KE, Hutchinson M. Stopping beta-interferon therapy in multiple sclerosis: An analysis of stopping patterns. Mult Scler 2005; 11(1): 46-50.

[http://dx.doi.org/10.1191/1352458505ms1131oa] [PMID: 157 32266]

[21] Tremlett HL, Oger J. Interrupted therapy: Stopping and switching of the beta-interferons prescribed for MS. Neurology 2003; 61(4): 551-4. [http://dx.doi.org/10.1212/01.WNL.0000078885.05053.7D] [PMID: 12939437]

[22] Patti F. Optimizing the benefit of multiple sclerosis therapy: The importance of treatment adherence. Patient Prefer Adher 2010; 4: 1-9. [http://dx.doi.org/10.2147/PPA.S8230] [PMID: 20165593]

[23] McKay KA, Tremlett H, Patten SB, et al. Determinants of nonadherence to disease-modifying therapies in multiple sclerosis: A cross-Canada prospective study. Mult Scler 2017; 23(4): 588-96. [http://dx.doi.org/10.1177/1352458516657440] [PMID: 273 57507]

[24] WHO. Adherence to long-term therapies. Evidence for action. 2003. Available from: http:/ /www.who.int/ chp/knowledge/ publications/ adherence_report/en/

[25] Sormani MP, Bruzzi P. Can we measure long-term treatment effects in multiple sclerosis? Nat Rev Neurol 2014

[http://dx.doi.org/10.1038/nrneurol.2014.237] [PMID: 255 34913]

[26] Higuera L, Carlin CS, Anderson S. Adherence to disease-modifying therapies for multiple sclerosis. J Manag Care Spec Pharm 2016; 22(12): 1394-401.

[http://dx.doi.org/10.18553/jmcp.2016.22.12.1394] [PMID: 27 882830]

[27] Cox D, Stone J. Managing self-injection difficulties in patients with relapsing-remitting multiple sclerosis. J Neurosci Nurs 2006; 38(3): 167-71.

[http://dx.doi.org/10.1097/01376517-200606000-00005] [PMID: 16817668]

[28] Foley FW. 2010. Psychosocial impact of multiple sclerosis: Challenges and solution, medscape education neurology \& neurosurgery. Avalaible at: https://www. medscape.org/ viewarticle/ 734647

[29] Mohr DC, Boudewyn AC, Likosky W, Levine E, Goodkin DE. Injectable medication for the treatment of multiple sclerosis: The influence of self-efficacy expectations and injection anxiety on adherence and ability to self-inject. Ann Behav Med 2001; 23(2): 125-32.

[http://dx.doi.org/10.1207/S15324796ABM2302_7] [PMID: 11 394554]

[30] Gerber B, Cowling T, Chen G, Yeung M, Duquette P, Haddad P. The impact of treatment adherence on clinical and economic outcomes in multiple sclerosis: Real world evidence from Alberta, Canada. Mult Scler Relat Disord 2017; 18: 218-24.

[http://dx.doi.org/10.1016/j.msard.2017.10.001] [PMID: 291 41814]

[31] Kobelt G, Berg J, Lindgren P, Fredrikson S, Jönsson B. Costs and quality of life of patients with multiple sclerosis in Europe. J Neurol Neurosurg Psychiatry 2006; 77(8): 918-26.

[http://dx.doi.org/10.1136/jnnp.2006.090365] [PMID: 1669 0691]

[32] Elliott RA, Shinogle JA, Peele P, Bhosle M, Hughes DA. Understanding medication compliance and persistence from an economics perspective. Value Health 2008; 11(4): 600-10. [http://dx.doi.org/10.1111/j.1524-4733.2007.00304.x] [PMID: 18194403]

[33] Guo A, Grabner M, Palli SR, et al. Treatment patterns and health care resource utilization associated with dalfampridine extended release in multiple sclerosis: A retrospective claims database analysis. Clinicoecon Outcomes Res 2016; 8: 177-86. [PMID: 27274292]

[34] Hall MA, Dugan E, Zheng B, Mishra AK. Trust in physicians and medical institutions: What is it, can it be measured, and does it matter? Milbank Q 2001; 79(4): 613-639, v.

[http://dx.doi.org/10.1111/1468-0009.00223] [PMID: 1178 9119]

[35] Howard I. Interpersonal factors in relationship to therapy outcome and therapeutic alliance in a cohort of multiple sclerosis patients. San Francisco, CA: Alliant International University, California School of Professional Psychology, San Francisco Bay 2003.

[36] Ice R. Long-term compliance. Phys Ther 1985; 65(12): 1832-9. [http://dx.doi.org/10.1093/ptj/65.12.1832] [PMID: 3906687]

[37] Costello K, Kennedy P, Scanzillo J. Recognizing nonadherence in patients with multiple sclerosis and maintaining treatment adherence in the long term. Medscape J Med 2008; 10(9): 225. [PMID: 19008986]

[38] Viswanathan M, Golin CE, Jones CD, et al. Interventions to improve adherence to self-administered medications for chronic diseases in the United States: A systematic review. Ann Intern Med 2012; 157(11): 785-95.

[http://dx.doi.org/10.7326/0003-4819-157-11-201212040-00538] [PMID: 22964778]

[39] Kale N. Optic neuritis as an early sign of multiple sclerosis. Eye Brain 2016; 8: 195-202.

[http://dx.doi.org/10.2147/EB.S54131] [PMID: 28539814]

[40] Lane DM. Pairwise comparisons (Correlated observations). Last accessed: 25 June 2018. Available from: http:// onlinestatbook.com/ 2/tests_of_means/pairwise_correlated.html

[41] Javed A, Reder AT. Rising JCV-Ab index during natalizumab therapy for MS: Inauspicious for a highly efficacious drug. Neurol Neuroimmunol Neuroinflamm 2016; 3(1): e199.

[http://dx.doi.org/10.1212/NXI.0000000000000199] 26848488]

[42] European Medicines Agency (EMA). Gilenya. Summary of product characteristics. Available from: http:// www.ema. europa.eu/ docs/it_IT /document_library/ EPAR_Product_Information/human/ 002202/ WC500104528.pdf 
[43] 2018. EUPAN. http:// www.eupan. eu/ Last accessed: June $20^{\text {th }}, 2018$.

[44] Giammanco MD, Gitto L. Patient satisfaction and uncertainty in illness in oncology: Which are the relevant aspects when planning a qualitatively adequate assistance? Italian Studies on Quality of Life. in press

[45] PRISMS (Prevention of Relapses and Disability by Interferon beta-1a Subcutaneously in Multiple Sclerosis) Study Group. Randomised double-blind placebo controlled study of interferon beta-1a in relapsing/remitting multiple sclerosis. Lancet 1998; 352: 1498-504. [http://dx.doi.org/10.1016/S0140-6736(98)03334-0] [PMID: 9 820297]

[46] Kappos L, Kuhle J, Multanen J, et al. Factors influencing long-term outcomes in relapsing-remitting multiple sclerosis: PRISMS-15. J Neurol Neurosurg Psychiatry 2015; 86(11): 1202-7.

[http://dx.doi.org/10.1136/jnnp-2014-310024] [PMID: 2637 4702]

[47] Johnson KP, Brooks BR, Cohen JA, et al. Copolymer 1 reduces relapse rate and improves disability in relapsing-remitting multiple sclerosis: Results of a phase III multicenter, double-blind placebocontrolled trial. The Copolymer 1 Multiple Sclerosis Study Group. Neurology 1995; 45(7): 1268-76.

[http://dx.doi.org/10.1212/WNL.45.7.1268] [PMID: 7617181]

[48] Ziemssen T, Bajenaru OA, Carrá A, et al. A 2-year observational study of patients with relapsing-remitting multiple sclerosis converting to glatiramer acetate from other disease-modifying therapies: The COPTIMIZE trial. J Neurol 2014; 261: 2101-11.

\section{○2019 Lara Gitto.}

This is an open access article distributed under the terms of the Creative Commons Attribution 4.0 International Public License (CC-BY 4.0), a copy of which is available at: https://creativecommons.org/licenses/by/4.0/legalcode. This license permits unrestricted use, distribution, and reproduction in any medium, provided the original author and source are credited. 